\title{
Survival of tumor cells after proton irradiation with ultra-high dose rates
}

\author{
Susanne Auer', Volker Hable ${ }^{2}$, Christoph Greubel², Guido A Drexler ${ }^{1}$, Thomas E Schmid ${ }^{3}$, Claus Belka', \\ Günther Dollinger ${ }^{2}$ and Anna A Friedl ${ }^{*}$
}

\begin{abstract}
Background: Laser acceleration of protons and heavy ions may in the future be used in radiation therapy. Laserdriven particle beams are pulsed and ultra high dose rates of $>10^{9} \mathrm{~Gy} \mathrm{~s}^{-1}$ may be achieved. Here we compare the radiobiological effects of pulsed and continuous proton beams.

Methods: The ion microbeam SNAKE at the Munich tandem accelerator was used to directly compare a pulsed and a continuous $20 \mathrm{MeV}$ proton beam, which delivered a dose of 3 Gy to a HeLa cell monolayer within < 1 ns or 100 ms, respectively. Investigated endpoints were G2 phase cell cycle arrest, apoptosis, and colony formation.

Results: At $10 \mathrm{~h}$ after pulsed irradiation, the fraction of $\mathrm{G} 2$ cells was significantly lower than after irradiation with the continuous beam, while all other endpoints including colony formation were not significantly different. We determined the relative biological effectiveness (RBE) for pulsed and continuous proton beams relative to $x$ irradiation as $0.91 \pm 0.26$ and $0.86 \pm 0.33$ (mean and SD), respectively.

Conclusions: At the dose rates investigated here, which are expected to correspond to those in radiation therapy using laser-driven particles, the RBE of the pulsed and the (conventional) continuous irradiation mode do not differ significantly.
\end{abstract}

Keywords: laser acceleration, proton therapy, dose rate effects

\section{Background}

Because of the superior dose distribution of protons and heavy ions, radiotherapy using charged particles has attracted increasing interest over the last years [1,2]. At the same time, however, a vivid discussion has started as to whether the potential improvements in outcome justify the costs of particle therapy, where the costs per fraction are estimated to be up to 5 times higher than those for photon therapy [3]. With the advent of ultrafast high energy lasers, the idea of laser-driven acceleration of particles suitable for therapeutic applications has arisen, combined with the hope for a reduction of costs and required space [4-6]. While early concepts may have been a bit over-enthusiastic [7], recent feasibility studies still see a potential for laser-acceleration in radiation therapy [8-10], although the energies achieved at present are far from

\footnotetext{
* Correspondence: anna.fried|@|rz.uni-muenchen.de

'Department of Radiation Oncology, Ludwig-Maximilians-Universität München, Germany

Full list of author information is available at the end of the article
}

those required for radiation therapy and many questions remain unresolved, e.g. regarding energy selection, beam preparation and transport, as well as repetition rate.

With respect to potential differences in the radiobiological effects of laser-accelerated particles and those accelerated conventionally by cyclotrons or synchrotrons, the main difference is that particle beams delivered from laser acceleration will be pulsed. While the laser pulses required for the acceleration of high energy particles are in the range of femtoseconds, the particle pulse thus created will spread in time during beam transport. For example, assuming protons with a mean energy of $100 \mathrm{MeV}$ and an energy spread of $1 \%$ which are transported over a $20 \mathrm{~m}$ distance, the expected duration of the pulse at the target will be about 1 ns [11]. Since the repetition rates of laser accelerators are expected to be rather moderate, one can envision that during one session each voxel of the PTV (planning treatment volume) can be targeted at most a few times if the treatment duration is to be kept reasonably short. Thus, with one pulse a considerable fraction of
C Biomed Central

() 2011 Auer et al; licensee BioMed Central Ltd. This is an Open Access article distributed under the terms of the Creative Commons Attribution License (http://creativecommons.org/licenses/by/2.0), which permits unrestricted use, distribution, and reproduction in any medium, provided the original work is properly cited. 
the required dose at a target voxel has to be given. Assuming a deposition of $>1$ Gy in 1 ns, this translates to an ultra high dose rate of $>10^{9} \mathrm{~Gy} \mathrm{~s}^{-1}$.

In the past, radiobiological effects of $\mathrm{x}$-ray or electrons delivered at ultra high dose rates were reported: Several authors described an enhanced resistance of cells irradiated with several Gy at dose rates in the range of $10^{9}$ $\mathrm{Gy} \mathrm{s}^{-1}$ at low oxygen concentrations [12,13] which was ascribed to oxygen depletion. Radical-radical recombination was also proposed as a possible explanation for reduced efficiency of pulsed irradiation [14]. It should be noted that these previous experiments were performed with conventional acceleration. Currently available laser accelerators have so far allowed for the performance of a few proof-of-principle experiments with laser plasma-generated X-rays $[15,16]$ and ultrasoft $X$ rays [17]. Tillmann and coworkers [15] applied a dose of only $3.4 \mathrm{mGy}$ per 2 ps pulse, which at repetition rates of $10 \mathrm{~Hz}$ lead to effective dose rates in the range of 2 Gy $\mathrm{min}^{-1}$. Hill and coworkers [17] achieved $0.07 \mathrm{~Gy}$ per $10 \mathrm{ps}$ pulse, i.e. with $7 \times 10^{9} \mathrm{~Gy} \mathrm{~s}^{-1}$ a dose rate where high dose rate effects may occur. Finally, Shinohara and coworkers [16] achieved up to 8 Gy per single sub-ps pulse, i.e. relevant dose rates of $10^{12}-10^{13}$ Gy s $^{-1}$. None of these authors found indications for significant effects of the dose rates associated with laser plasmagenerated X-rays as compared to conventional irradiations on cell survival. However, the photon beams used for comparison differed in all three cases in terms of mean energy and energy distribution, so that in the case of small alterations it would be difficult to determine if these are due to differences in dose rate or in energy spectrum. Recently, also proof-of-principle experiments with laser driven protons or electrons were performed, in which it was shown that these beams generate DNA double-strand breaks, as would have been expected [18-20]. A quantitative evaluation and comparison with conventionally accelerated protons was, however, not provided.

In order to simulate the pulsed irradiation conditions expected for laser-accelerated protons in therapy settings, we have established a pulsed proton beam at the ion microbeam SNAKE at the Munich tandem accelerator [11]. By focusing a bunch of $10^{5} \mathrm{p}+$ onto a spot of approximately $100 \mu \mathrm{m} \times 100 \mu \mathrm{m}$ we apply macroscopic doses of a few Gy within $<1$ ns. The irradiations are performed with monoenergetic protons, which enables us to perform irradiations with conventional dose rates for direct comparison with the same beam quality. Using this system, in previous work we reported that the induction of micronuclei in HeLa cell monolayers or in keratinocytes within 3D tissue is not significantly different between pulsed and conventional proton irradiation [21,22]. In an analysis of chromosome aberrations, however, we found evidence that proton irradiation in the pulsed mode may be slightly less effective than in the continuous irradiation mode [23]. Here we extend these studies to the analysis of radiation induced cell cycle arrests and apoptosis. In addition, and most importantly, we also investigate the clonogenic survival of cells irradiated under both conditions. This endpoint is generally considered to be of utmost relevance when judging irradiation conditions.

\section{Methods}

\section{Cell culture for irradiation}

HeLa cells (subtype HeLa-RIKEN) were cultured in RPMI

TS 1640 medium (PAA), supplemented with 10\% fetal bovine serum, $2 \mathrm{mM}$ L-glutamine, $100 \mathrm{U} / \mathrm{ml}$ penicillin, and $50 \mu \mathrm{g} / \mathrm{ml}$ streptomycin in a humidified incubator $(5 \%$ $\mathrm{CO}_{2}, 37^{\circ} \mathrm{C}$ ). Twelve hours prior to irradiation, cells were seeded in stainless steel cell containers designed for irradiation at SNAKE [24]. In these containers, cells grow on a $6 \mu \mathrm{m}$ thick Mylar foil (carrier foil), covered with Cell$\mathrm{TAK}^{\mathrm{TM}}$ Tissue Adhesive (BD Biosciences) for better attachment. In order to provide restricted growth areas in these containers, two different cylindrical adapters can be mounted onto the container. The growth areas thus obtained are $3.14 \mathrm{~cm}^{2}$ for $2 \times 10^{5}$ cells in immunofluorescence experiments, or $0.65 \mathrm{~cm}^{2}$ for $3 \times 10^{4}$ cells in clonogenic survival experiments. Since the irradiation setup at SNAKE requires a vertical sample position, the adapters were removed from the incubator directly before treatment and the containers were sealed with another Mylar foil glued to a stainless steel lid. During irradiation, which takes less than $10 \mathrm{~min}$, the cells are not covered by medium, but a medium reservoir ensures a humid atmosphere. After irradiation cells were given fresh medium and they were incubated for 0 to 48 hours until fixation for immunofluorescence. For clonogenic survival experiments the cells were harvested one hour after radiation treatment and appropriate numbers of cells were reseeded in 6-well tissue containers. The same cell cultivation procedures and same containers were used in proton irradiation and $\mathrm{X}$-ray experiments.

\section{Irradiation with $250 \mathrm{kV}$ X-rays}

$\mathrm{X}$-ray irradiation was performed with a Philips MCN-ray tube $(250 \mathrm{kV}, 13 \mathrm{~mA}, 2.5+4.0 \mathrm{~mm} \mathrm{Al}$ and $1.0 \mathrm{~mm} \mathrm{Cu}$ filtration) at a dose rate of $0.56 \mathrm{~Gy} \mathrm{~min}^{-1}$. HeLa cells grown on Mylar foil were irradiated with doses from 0 to $5 \mathrm{~Gy}$ for a reference survival curve ( 2 independent experiments) and with $3 \mathrm{~Gy}$ for immunofluorescence detection of cell cycle arrest and apoptosis (5 to 7 independent experiments, each with a non-irradiated control).

\section{Irradiation with pulsed and continuous proton beams}

Proton irradiation was performed using the microprobe SNAKE at the Munich tandem accelerator in a pulsed 
and a continuous irradiation mode. Beam preparation and dosimetry [11], as well as cell irradiation with pulsed and continuous proton beams at SNAKE [21] were performed as described previously. For pulsed irradiations, about $10^{5}$ protons were focused onto a beam spot of approximately $100 \times 100 \mu^{2}$, which was then scanned with $100 \mathrm{~Hz}$ over a region of $1.5 \times 2 \mathrm{~mm}^{2}$ for immunofluorescence staining experiments. This scanning results in a nearly homogeneous dose distribution, where between $25 \%$ and $60 \%$ (on average nearly $50 \%$ ) of the total dose ( $3 \mathrm{~Gy}$ ) to each cell was given by a single $<1 \mathrm{~ns}$ pulse, corresponding to an instantaneous dose rate of $>10^{9} \mathrm{~Gy} \mathrm{~s}^{-1}$, while the remaining dose resulted from contributions of adjacent irradiation fields. In colony formation experiments larger irradiation fields were required in order to entirely cover the circular cell cultivation area of $0.65 \mathrm{~cm}^{2}$. Therefore, a region of approximately $10 \mathrm{~mm} \times 10 \mathrm{~mm}$ was irradiated by arranging several $1.5 \times 2.0 \mathrm{~mm}^{2}$ fields next to each other by moving the cell sample mechanically. In irradiations with the continuous beam, a rectangular beam spot with a size of approximately $2 \times 2 \mathrm{~mm}^{2}$ was used, and the time required to deliver the total dose to cells was in the order of $100 \mathrm{~ms}$ (dose rate $\sim 30 \mathrm{~Gy} \mathrm{~s}^{-1}$ ).

Experiments for detection of cell cycle arrest and apoptosis were performed with $20 \mathrm{MeV}$ protons (LET in water

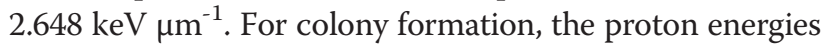
were varied between 20 and $25 \mathrm{MeV}$ between experiments for technical reasons. Dose was changed by adjusting the proton fluence accordingly. The variation in LET (between $2.648 \mathrm{keV} \mathrm{\mu m}^{-1}$ and $2.207 \mathrm{keV} \mathrm{um}^{-1}$ ) was considered to be negligible.

Parallel irradiation experiments with pulsed and continuous beams were always conducted within the same beam time, but for technical reasons they had to be separated by 2-3 days, i.e. the time needed to switch from pulsed to continuous beam preparation.

\section{Immunofluorescence detection of cell cycle arrest and apoptosis}

For immunofluorescence analyses, cells were fixed with $2 \%$ paraformaldehyde (PBS-buffered; $15 \mathrm{~min}$ ) immediately after the irradiation experiment (i.e. on average about 5 min after irradiation, due to the duration of the irradiation and the sample handling) or after incubation for 10, 24, or 48 hours. Permeabilisation (0.15\% TritonX 100 in PBS) and blocking (1\% BSA, $0.15 \%$ Glycine in PBS) were done as described previously [24]. Epifluorescence microscopy was performed with a Zeiss AxioObserver Z1 inverse epifluorescence microscope (Germany), using a Zeiss LCI Plan Neofluar 63/1.3 objective, the software AxioVision 4.6 and an AxioCam Mrm camera (Zeiss). All images were further processed using the software ImageJ 1.37c (http:// www.uhnresearch.ca/wcif).
Cells in G2/M phase were identified by immunostaining with mouse anti-CyclinB1 antibody (dilution 1:100, Abcam \#ab49215). G2-specific staining was in initial experiments verified by co-staining with rabbit antiCENP-F antibody (1:500, Novus Biologicals, \#NB500-101), which identifies cells in S/G2/M phase. In cell samples irradiated with protons, the irradiated region was detected by co-staining with rabbit anti- $\gamma-\mathrm{H} 2 \mathrm{AX}$ antibody $(1: 200$, Abcam, \# ab11174). After application of fluorescence conjugated secondary antibodies sheep-anti-mouse Cy3 (1:500, Dianova, \#515-165-062) and goat-anti-rabbit Alexa488 (1:200, Molecular Probes, \#A-11034), DNA was stained with DAPI. The fraction of CyclinB1 positive cells (excluding mitotic cells as identified by chromatin structure), was separately determined for the irradiated area and a non-irradiated area (n. i.) of the same sample. The data presented give the mean and standard error of the mean (SEM) of 3 independent proton experiments performed within 3 different beam times and 5 to 7 independent $\mathrm{x}$-ray experiments.

Apoptotic cells were initially identified by staining with rabbit anti-cleaved caspase3 (1:100, Trevigen, \#2305-PC050) and goat-anti-rabbit Alexa488 (1:200, Molecular Probes, \#A-11034). DNA was stained with DAPI. Since the same results were obtained when identifying apoptotic cells based on the characteristic chromatin structure after DAPI staining, in later experiments the apoptotic cells were identified simply by chromatin structure. In samples irradiated with protons, the irradiated area was detected by immunostaining with rabbit anti- $\gamma-\mathrm{H} 2 \mathrm{AX}$ antibody (1:200, Abcam, \# ab11174). The percentage of apoptotic cells was determined in 2 to 5 proton experiments per point of time, performed within 4 different beam times, and 5 to 7 independent $x$-ray experiments (mean and SEM).

\section{FACS analysis of cell cycle distribution}

For quantitation of cells in G2/M phase by FACS analysis, cells were harvested 10 and 24 hours after irradiation with $\mathrm{x}$-rays (3 Gy and sham-irradiated controls) and washed with PBS. Cells were resuspended in $0.5 \mathrm{ml}$ DNA-staining solution I (PBS containing $10 \mu \mathrm{g} / \mathrm{ml}$ RNAse, $0.6 \mathrm{mg} / \mathrm{ml}$ $\mathrm{NaCl}, 1 \mathrm{mg} / \mathrm{ml}$ Sodium citrate, $0.07 \%$ Nonidet $^{\circledR} \mathrm{P} 40$ Substitute, $20 \mu \mathrm{g} / \mathrm{ml}$ propidium iodide (PI)) and incubated at room temperature in the dark for $30 \mathrm{~min}$, before $0.5 \mathrm{ml}$ of ice-cold DNA-staining solution II (PBS containing $15 \mu \mathrm{g} /$ $\mathrm{ml}$ citric acid, $85 \mu \mathrm{g} / \mathrm{ml}$ sucrose, $20 \mu \mathrm{g} / \mathrm{ml} \mathrm{PI)} \mathrm{was} \mathrm{added.}$ Samples were stored at $4^{\circ} \mathrm{C}$ until PI-detection with BD FACSCanto $^{\mathrm{TM}}$. Data were analysed with BD FACSDiva ${ }^{\mathrm{TM}}$ software.

\section{Clonogenic survival}

About $24 \mathrm{~h}$ prior to irradiation, $3 \times 10^{4} \mathrm{HeLa}$ cells were seeded in irradiation containers on Mylar foil, restricted 
to an area of $0.65 \mathrm{~cm}^{2}$ by a special cylindrical adapter. To characterize survival after irradiation with pulsed and continuous protons, we have chosen a dose of $3 \mathrm{~Gy}$, analogous to the other investigated endpoints. For creating a reference survival curve, cells were irradiated with $250 \mathrm{kV}$ x-rays, with doses ranging from 0 to $5 \mathrm{~Gy}$. One hour after irradiation, cells were harvested by trypsination and counted with a Bürker chamber. Cells were reseeded in 3 different titres and in triplicates into 6-wells containers. The cells were maintained at $37^{\circ} \mathrm{C}$ and $5 \% \mathrm{CO}_{2}$ for 10 days to allow colony formation. After this time period, the cells were fixed and stained with ethanol (80\%) containing $0.3 \%$ methylene blue for 30 minutes. After washing, the samples were air-dried and microscopically examined. Colonies consisting of more than 50 cells were considered as survivors. The plating efficiency $(\mathrm{PE}=$ cells seeded/colonies counted) was calculated for non-irradiated cells and the surviving fraction of irradiated cells $(\mathrm{SF}=$ [cells seeded/colonies counted]/PE) was determined. Each experiment was performed at least twice and mean and standard deviation (SD) are presented.

The RBE of protons (pulsed or continuous) is calculated as the ratio between the dose, $\mathrm{D} \gamma$, of the reference radiation (250 kV X-rays) and the dose, Dp, of protons which produced equal response, $\mathrm{y}: \mathrm{RBE}=\mathrm{D} \gamma / \mathrm{Dp}$. To calculate $\mathrm{D} \gamma$ the measured dose response curve is parameterised by a linear-quadratic function $y=c+\alpha D+$ $\beta D 2$, fitted to determine the parameter $c, \alpha$ and $\beta$ and inverted.

As the fit parameters, $c, \alpha$ and $\beta$, depend on each other, a Monte Carlo simulation-based Bayesian data analysis is performed. In a first step the three-dimensional probability density is calculated as a function of $c, \alpha$ and $\beta$ for measuring the data set used for the dose response curve. In a second step, assuming a Gaussian probability density for $y$, the probability density for $\mathrm{D} \gamma$ is calculated leading to the confidence interval for $\mathrm{D} \gamma$. From this and from the error of the proton dose measurement the error of the RBE value is calculated by Gaussian error propagation.

\section{Results}

\section{Experimental Set-up}

In order to apply macroscopic doses of a few Gy within $1 \mathrm{~ns}$, we use a proton microbeam facility with which $10^{5}$ $\mathrm{p}+$ can be focused onto a spot of approximately $100 \mu \mathrm{m}$ $\times 100 \mu \mathrm{m}$ and delivered within $0.9 \mathrm{~ns}$ [11]. This beam spot is scanned over a larger area to irradiate a sufficient number of cells. In our first experiments, the irradiated field was for technical reasons limited to $1.5 \times 2 \mathrm{~mm}^{2}$. Since this irradiated field is surrounded by a large area (diameter $\sim 3 \mathrm{~cm}$ ) of unirradiated cells, only biological endpoints amenable to a microscopic evaluation could thus be investigated. We chose microscopic analysis of cell cycle distribution and of apoptosis induction. The irradiated field is identified by concomitant immunofluorescence detection of DNA damage markers such as $\gamma$-H2AX or 53BP1.

In later experiments, including experiments on colony formation ability, the field size was increased to $10 \times 10$ $\mathrm{mm}^{2}$ by introducing additional mechanical scanning of the cell sample. Analysis of colony formation required that all cells on the dish were irradiated before harvest and reseeding. We therefore devised specific cylindrical adaptors with which the growth field on the Mylar foil could be clearly defined. Cells were seeded within this cylinder ( $9 \mathrm{~mm}$ diameter) and allowed to grow and form a sub-confluent layer there. Immediately before the irradiation, the cylinders were removed. For irradiation, the cell field was aligned to the beam by using an optical microscope.

\section{Cell cycle arrest}

Cyclin B1 expression begins in S phase and peaks in G2 phase. Prior to $M$ phase, cyclin B1 is predominantly located in the cytoplasm; after centrosome separation it accumulates in the nucleus, before it is degraded at the transition of meta- to anaphase. Radiation-induced G2 arrest and relative cyclin B1 expression were shown to correlate well in Hela cells [25]. To test the correlation between DNA content and microscopically detectable cyclin B1 localization in cytoplasm or nucleus, parallel samples were subject to PI staining and flow cytometry, or to immunofluorescence with cyclin B1 staining (Additional file 1). A clear accumulation of G2/M phase cells is detected $10 \mathrm{~h}$ after irradiation (3 Gy $\mathrm{x}$-ray) in irradiated cells, while after $24 \mathrm{~h}$ the percentage of G2/M cells in irradiated samples returned to a level similar to unirradiated controls. When mitotic cyclin B negative cells, which were identified microscopically by the typical chromatin appearance, were added to the numbers of cyclin B1 positive cells, both methods gave very similar results, demonstrating that microscopic determination of cyclin B1 staining can be used to determine G2 phase cells.

To compare the induction of G2 arrest in cells irradiated by 3 Gy pulsed and continuous proton irradiation, the cells were irradiated under the respective conditions, and fixed at the earliest time point amenable (on average about $5 \mathrm{~min}$ ) or, after removal of the lid and medium exchange, incubated for $10 \mathrm{~h}, 24 \mathrm{~h}$, or $48 \mathrm{~h}$ at $37^{\circ}, 5 \%$ $\mathrm{CO}_{2}$ before fixation. Samples were simultaneously stained for cyclin B1 to determine the cell cycle position and $\gamma-\mathrm{H} 2 \mathrm{AX}$ to identify the irradiated field. Typical examples are shown in Figure 1. The proportion of G2 phase cells (defined as cyclin B1 positive, without mitotic cells) among cells exhibiting damage markers was 


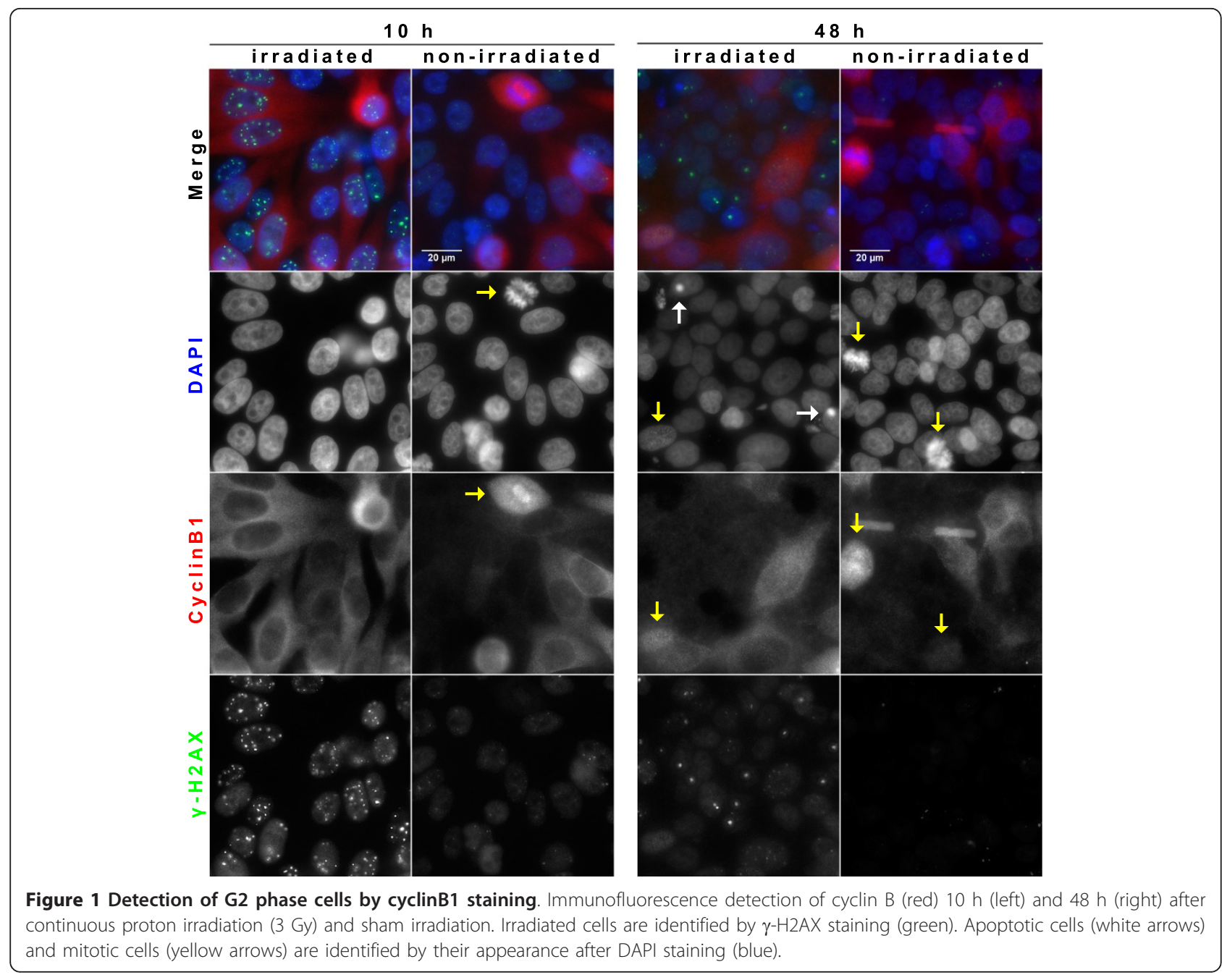

determined by manual counting of at least 130 cells per experiment. After proton irradiation the maximum G2 phase arrest is evident after $10 \mathrm{~h}$, while after $24 \mathrm{~h}$ the proportion of G2 phase cells is similar to the situation before irradiation (Figure 2). Interestingly, at $10 \mathrm{~h}$ after irradiation the proportion of G2 phase cells after continuous proton irradiation was found to be significantly higher than after pulsed irradiation ( $\mathrm{t}$-test, two-tailed $\mathrm{p}=$ 0.0182). To test whether the difference can be explained by small differences in absolute dose between the samples irradiated at pulsed and continuous mode, we asked whether a substantial increase in dose would affect the outcome and compared the induction of G2 phase arrest after x-irradiation of HeLa cells with 3 and 5 Gy (Additional file 2). Since the fraction of G2 phase cells after 10 $h$ is practically the same at both doses, we conclude that the differences between pulsed and continuous mode cannot be explained by small variations in dose. We note that the duration of the G2 phase arrest appears to be influenced by dose.

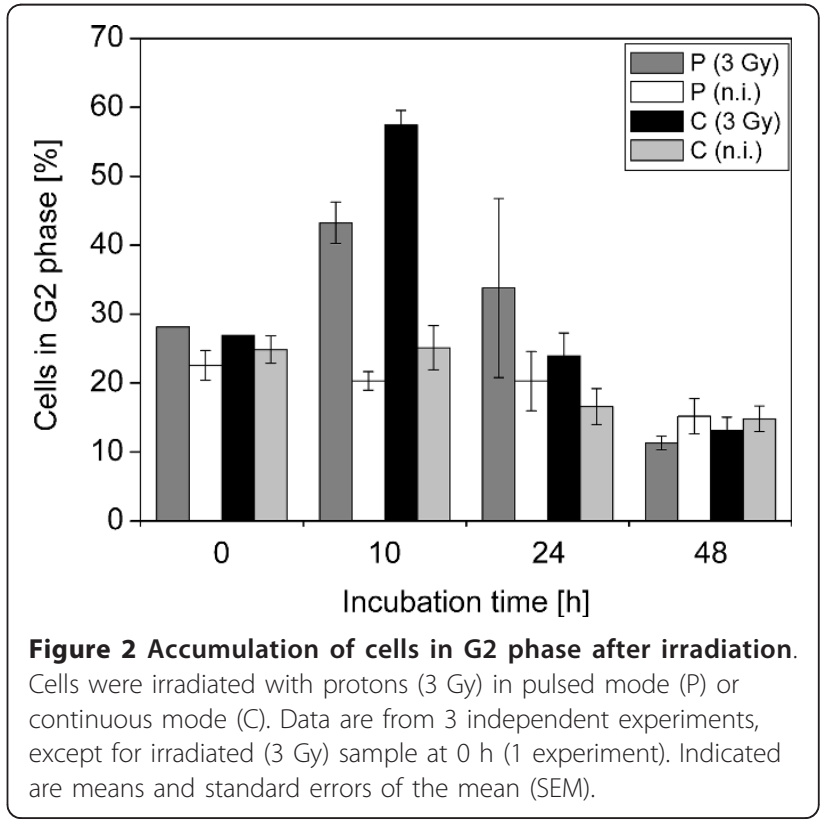




\section{Radiation induced apoptosis}

Since the number of samples that can be irradiated at SNAKE is very limited, we aimed at determining the induction of apoptosis in the samples used for determination of G2 arrest. In preliminary experiments we verified by co-staining with an antibody recognizing the apoptosis indicator, cleaved caspase 3 , that apoptotic cells can be identified after DAPI staining by the appearance of bright circular bodies (Additional file 3). After irradiation with $\mathrm{x}$ rays, the proportion of apoptotic cells increases with time, but the inter-experimental variation is very high (Additional file 4). One likely explanation is that in the course of the immunofluorescence detection, which involves several washing steps, apoptotic cells can easily be lost. Comparing induction of apoptosis after proton irradiation in the continuous mode and the pulsed mode, no significant difference was seen (Figure 3).

\section{Colony formation}

Colony formation is one of the most important endpoints in studying radiobiological effects. After irradiation with 3 Gy using pulsed and continuous proton beams, the fraction of colony forming cells was $0.43 \pm 0.07$ (mean and SEM) and $0.47 \pm 0.06$, respectively. This difference is not statistically significant. For comparison the survival curve after $\mathrm{x}$-irradiation is also shown (Figure 4). We determined the relative biological effectiveness (RBE) for pulsed and continuous proton beams relative to $\mathrm{x}$-irradiation as 0.91 \pm 0.26 and $0.86 \pm 0.33$ (mean and SD), respectively. These values are not significantly different.

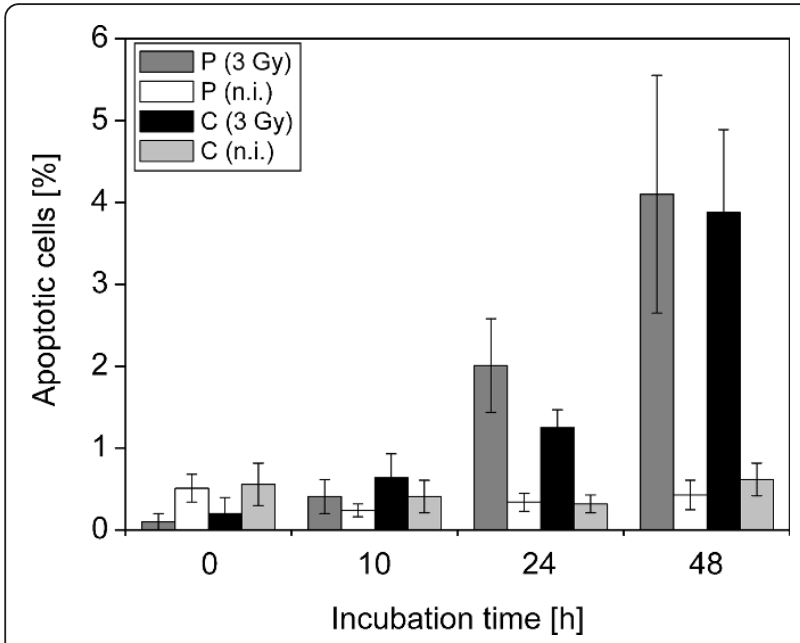

Figure 3 Induction of apoptosis after irradiation. Cells were irradiated with protons (3 Gy) in pulsed mode (P) or continuous mode (C). Data are from 5 independent experiments except for data at $10 \mathrm{~h}$ (4 experiments) and irradiated samples at $0 \mathrm{~h}$ (2 experiments). Indicated are means and standard errors of the mean (SEM).

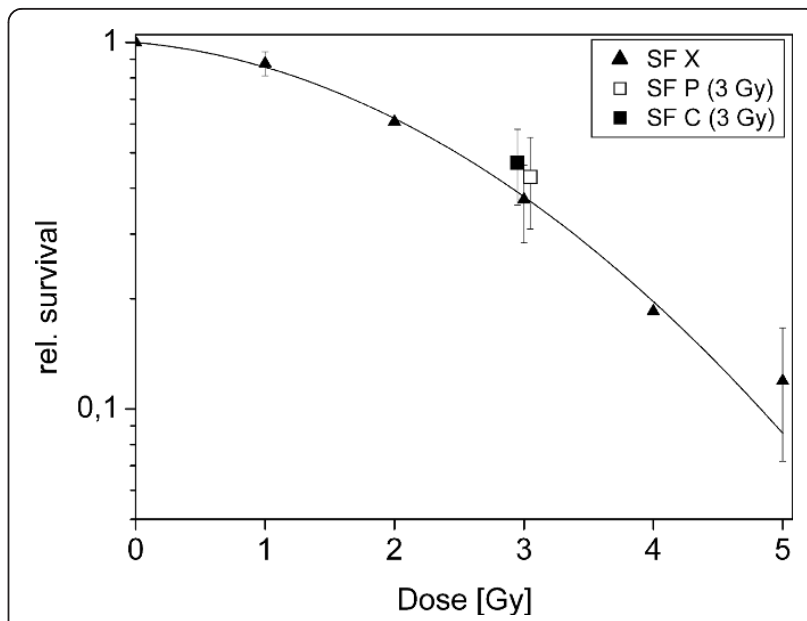

Figure 4 Colony formation after irradiation with pulsed and continuous proton beams. Indicated is relative survival (surviving fraction, SF) of HeLa cells after irradiation with pulsed (SF P, open square) or continuous (SF C black square) proton beams at $3 \mathrm{~Gy}$. Mean and SD of 3 independent experiments in 3 different beam times. Reference: $x$-ray irradiation (SF X, black triangles), mean and SD of 2 independent experiments.

\section{Discussion}

The present work is part of a series of systematic comparisons of biological endpoints after irradiation with pulsed and continuous proton beams, which in their dose rate differ by a factor of $10^{8}$. Using Monte Carlo-based modelling, Kreipl et al. conducted a systematic analysis of the impact of spatial and temporal proximity of ion tracks on the yield of hydroxyl radicals [26]. While indeed the yield of hydroxyl radicals is expected to be reduced when two ion tracks overlap closely in time and space, the authors conclude that at typical doses associated with radiation therapy ( 2 - 5 Gy), the spatial separation of two tracks is larger than would be necessary for the reduction in hydroxyl radical yield to occur. This holds for proton tracks, and even more so for heavier ions. Indeed, in our previous analyses we did not detect statistically significant differences between both irradiation modes when investigating a variety of specific endpoints related to chromosomal damage, i.e. micronuclei and chromosomal aberrations [21-23]. We consistently observed, however, a slightly reduced apparent efficiency of the pulsed beam in inducing the damage compared to the continuous beam. When combining data for different types of chromosomal aberrations (dicentrics, centric rings and excess acentrics) and thus increasing the sample size, we recently observed a statistically significantly reduced effectiveness of pulsed irradiation [23].

Here, we report for the first time a reduced effectiveness of the pulsed irradiation mode on a single endpoint, namely G2 phase arrest at $10 \mathrm{~h}$ after irradiation (Figure 2), thus substantiating the previous observations. This 
difference is somewhat surprising, given that the fraction of cell arresting in G2 appears to be rather insensitive to dose, at least in the dose range of 3 to 5 Gy $x$-irradiation (Additional file 2). While exhibiting a high degree of variation, we find indications that the duration of the G2 arrest may be longer after irradiation in the pulsed mode than in the continuous mode (Figure 2), possibly hinting at a shift in the time to maximum G2 arrest and in duration. Further experiments are necessary to clarify this point. We cannot exclude at present that the observed difference reflects differences in damage complexity, as it is well known that the duration of the G2 arrest is affected by LET [27]. There is no evidence that systematic errors in dosimetry had influence on this result, because the same setup was used for preparation of the pulsed and the continuous beam for proton irradiation.

In any case, the difference in cell cycle response did not translate into a difference in colony forming ability (Figure 4). While the pulsed beam was slightly more efficient in cell killing, the difference was not significant. With $0.91 \pm 0.26$ and $0.86 \pm 0.33$ for pulsed and continuous mode, respectively, and considering that $\mathrm{x}$-rays were used as reference irradiation rather than gamma rays, the RBE determined for both irradiation modes is compatible with the generally assumed RBE of 1.1, which is also applied in proton therapy [28]. We cannot exclude at the moment that at even higher dose rates in pulsed mode, differences would become apparent.

While production of ultra high dose rate pulses emerges as an interesting new application of microbeams that can even be used for irradiation of mice [29,30], the dose rates achievable with our set-up are limited. Experiments to investigate the effects of laser-driven protons, which would deliver their dose in the ps range if the distance between proton source and cell targets is not too large, are currently under way in our laboratory. It is important to note, however, that in a clinical application of laser-driven protons, the proton source is also expected to be not very close to the patient, since high levels of unspecific dose distributions from primary and secondary neutron and high energy $\mathrm{x}$-ray fields and the need for selection of protons with appropriate energy from the broad energy distribution typically obtained by laser acceleration will require a beam line which for radiation protection reasons may not be much shorter than the beam lines known from conventional acceleration. We currently estimate the pulse duration at the tumor voxel in the range of $1 \mathrm{~ns}$ [11].

\section{Conclusion}

At the dose rates investigated here, which are expected to correspond to those in radiation therapy using laser-driven particles, the RBE of the pulsed and the (conventional) continuous irradiation mode do not differ significantly.

\section{Additional material}

Additional file 1: Agreement of quantitative determination of G2/M phase cells by FACS analysis and microscopy. This figure shows the results of a quantitative evaluation of the number of G2/M phase cells determined by FACS analysis and microscopy in parallel samples.

Additional file 2: Dose-dependence of accumulation of cells in G2 phase after $\mathbf{x}$-irradiation. This figure shows the frequency of cells in G2 phase after irradiation with 0, 3 and 5 Gy and incubation for 0, 10, 24 and $48 \mathrm{~h}$.

Additional file 3: Microscopic identification of apoptotic cells. This figure shows examples of apoptotic cells identified by staining for cleaved caspase 3 and by appearance after DAPI staining.

Additional file 4: Dose-dependence of induction of apoptotic cells after $\mathbf{x}$-irradiation. This figure shows the frequency of apoptotic cells after irradiation with 0,3 and 5 Gy and incubation for 0, 10, 24 and 48 h.

\section{List of abbreviations}

DAPI: 4',6-Diamidin-2-phenylindol; FACS: Fluorescence-activated cell sorter; LET: linear energy transfer; RBE: relative biological effectiveness; SEM: standard error of the mean; SD: standard deviation

\section{Acknowledgements and funding}

Supported by the DFG-Cluster of Excellence 'Munich Advanced Photonics' and the Maier Leibnitz Laboratory (MLL) Munich. We thank the MLL staff for operation of the accelerator, Sara Sanchez-Molina and Peter Becker for help with FACS analysis, Olga Zlobinskaya for statistical evaluation of survival data and Sophie Lindemaier for assistance during beam times.

\section{Author details}

${ }^{1}$ Department of Radiation Oncology, Ludwig-Maximilians-Universität München, Germany. ${ }^{2}$ Institute for Applied Physics and Metrology, Universität der Bundeswehr München, Neubiberg, Germany. ${ }^{3}$ Department of Radiation Oncology, Technische Universität München, Germany.

\section{Authors' contributions}

SA performed and evaluated most of the biological experiments. VH, CG and GD performed the microbeam irradiations. GAD helped with beam time organization and experiments. TES helped with beam time organization and statistical evaluation of colony formation experiments. CB and GD contributed to study design and manuscript preparation. AAF was the Principal Investigator of the study and prepared the manuscript. All authors read and approved of the manuscript.

\section{Competing interests}

The authors declare that they have no competing interests.

Received: 20 July 2011 Accepted: 18 October 2011

Published: 18 October 2011

\section{References}

1. Bouyon-Monteau A, Habrand JL, Datchary J, Alapetite C, Bolle S, Dendale R, Feuvret L, Helfre S, Calugaru V, Cosset JM, Bey P: [ls proton beam therapy the future of radiotherapy? Part I: clinical aspects] (French). Cancer Radiother 2010, 14(8):727-738.

2. Durante $M$, Loeffler JS: Charged particles in radiation oncology. Nat Rev Clin Oncol 2010, 7(1):37-43.

3. Peeters A, Grutters JP, Pijls-Johannesma M, Reimoser S, De Ruysscher D, Severens $J$, Joore MA, Lambin P: How costly is particle therapy? Cost analysis of external beam radiotherapy with carbon-ions, protons and photons. Radiother Oncol 2010, 95(1):45-53.

4. Fourkal E, Shahine B, Ding M, Li JS, Tajima T, Ma CM: Particle in cell simulation of laser-accelerated proton beams for radiation therapy. Med Phys 2002, 29(12):2788-2798.

5. Malka V, Fritzler S, Lefebvre E, d'Humières E, Ferrand R, Grillon G, Albaret C, Meyroneinc S, Chambaret JP, Antonetti A, Hulin D: Practicability of 
protontherapy using compact laser systems. Med Phys 2004, 31(6):1587-1592

6. Chiu C, Fomytskyi M, Grigsby F, Raischel F, Downer MC, Tajima T: Laser electron accelerators for radiation medicine: a feasibility study. Med Phys 2004, 31(7):2042-2052.

7. Linz U, Alonso J: What will it take for laser driven proton accelerators to be applied to tumor therapy? Phys Rev ST Accel Beams 2007, 10:094801.

8. Schell S, Wilkens JJ: Modifying proton fluence spectra to generate spread-out Bragg peaks with laser accelerated proton beams. Phys Med Biol 2009, 54(19):N459-466.

9. Schell S, Wilkens JJ: Advanced treatment planning methods for efficient radiation therapy with laser accelerated proton and ion beams. Med Phys 2010, 37(10):5330-5340.

10. Tajima T, Habs D, Yan X: Laser Acceleration of lons for Radiation Therapy. Reviews of Accelerator Science and Technology 2009, 2:201-228.

11. Dollinger G, Bergmaier A, Hable V, Hertenberger R, Greubel C, Hauptner A, Reichart P: Nanosecond pulsed proton microbeam. Nucl Instr and Meth $B$ 2009, 267:2008-2012.

12. Epp ER, Weiss H, Ling CC: Irradiation of cells by single and double pulses of high intensity radiation: Oxygen sensitization and diffusion kinetics. Curr Top Radiat Res Q 1976, 11:201-250.

13. Berry RJ: Effects of radiation dose-rate. From protracted, continuous irradiation to ultra high dose-rates from pulsed accelerators. Br Med Bull 1973, 29(1):44-47.

14. Berry RJ, Hall EJ, Forster DW, Storr TH, Goodman MJ: Survival of mammalian cells exposed to $\mathrm{x}$-rays at ultra-high dose-rates. $\mathrm{Br} J$ Radiol 1969, 42:102-107.

15. Tillman C, Grafström G, Jonsson AC, Jönsson BA, Mercer I, Mattsson S, Strand SE, Svanberg S: Survival of mammalian cells exposed to ultrahigh dose rates from a laser-produced plasma x-ray source. Radiology 1999, 213(3):860-865.

16. Shinohara K, Nakano H, Miyazaki N, Tago M, Kodama R: Effects of singlepulse ( $<$ or $=1 \mathrm{ps}$ ) $\mathrm{X}$-rays from laser-produced plasmas on mammalian cells. J Radiat Res (Tokyo) 2004, 45(4):509-514.

17. Hill MA, Stevens DL, Marsden SJ, Allot R, Turcu IC, Goodhead DT: Is the increased relative biological effectiveness of high LET particles due to spatial or temporal effects? Characterization and OER in V79-4 cells. Phys Med Biol 2002, 47(19):3543-3555.

18. Yogo A, Sato K, Nishikino M, Mori M, Teshima T, Numasaki H, Murakami M, et al: Application of laser-accelerated protons to the demonstration of DNA double-strand breaks in human cancer cells. Appl Phys Lett 2009, 94:181502.

19. Kraft SD, Richter C, Zeil K, Baumann M, Beyreuther E, Bock S, Bussmann M, Cowan TE, Dammene Y, Enghardt W, Helbig U, Karsch L, Kluge T, Laschinsky L, Lessmann E, Metzkes J, Naumburger D, Sauerbrey R, Schürer M, Sobiella M, Woithe J, Schramm U, Pawelke J: Dose-dependent biological damage of tumour cells by laser-accelerated proton beams Focus on Laser- and Beam-Driven Plasma Accelerators. New J Phys 2010, 12:085003.

20. Rigaud O, Fortunel NO, Vaigot P, Cadio E, Martin MT, Lundh O, Faure J, Rechatin C, Malka V, Gauduel YA: Exploring ultrashort high-energy electron-induced damage in human carcinoma cells. Cell Death Disease 2010, 1:e73.

21. Schmid TE, Dollinger G, Hauptner A, Hable V, Greubel C, Auer S, Friedl AA Molls M, Röper B: No evidence for a different RBE between pulsed and continuous $20 \mathrm{MeV}$ protons. Radiat Res 2009, 172(5):567-574.

22. Schmid TE, Dollinger G, Hable V, Greubel C, Zlobinskaya O, Michalski D, Molls M, Röper B: Relative biological effectiveness of pulsed and continuous $20 \mathrm{MeV}$ protons for micronucleus induction in 3D human reconstructed skin tissue. Radiother Oncol 2010, 95(1):66-72.

23. Schmid TE, Dollinger G, Hable V, Greubel C, Zlobinskaya O, Michalski D, Auer S, Friedl AA, Schmid E, Molls M, Röper B: The Effectiveness of $20 \mathrm{MeV}$ Protons at Nanosecond Pulse Lengths in Producing Chromosome Aberrations in Human-Hamster Hybrid Cells. Radiat Res 2011, 175(6):719-727.

24. Hauptner A, Dietzel $S$, Drexler GA, Reichart $P$, Krücken R, Cremer T, Friedl AA, Dollinger G: Microirradiation of cells with energetic heavy ions. Radiat Environ Biophys 2004, 42(4):237-245.

25. Narayanan PK, Rudnick JM, Walthers EA, Crissman HA: Modulation in cell cycle and cyclin B1 expression in irradiated HeLa cells and normal human skin fibroblasts treated with staurosporine and caffeine. Exp Cell Res 1997, 233(1):118-127.

26. Kreipl MS, Friedland W, Paretzke HG: Interaction of ion tracks in spatial and temporal proximity. Radiat Environ Biophys 2009, 48(4):349-359.

27. Fournier C, Taucher-Scholz G: Radiation induced cell cycle arrest: an overview of specific effects following high-LET exposure. Radiother Oncol 2004, 73(Suppl 2):S119-122.

28. Paganetti $\mathrm{H}$ : Significance and implementation of RBE variations in proton beam therapy. Technol Cancer Res Treat 2003, 2(5):413-426.

29. Durante $M$, Friedl AA: New challenges in radiobiology research with microbeams. Radiat Environ Biophys 2011, 50(3):335-338.

30. Greubel C, Assmann W, Burgdorf C, Dollinger G, Du G, Hable V, Hapfelmeier A, Hertenberger R, Kneschaurek P, Michalski D, Molls M, Reinhardt S, Röper B, Schell S, Schmid TE, Siebenwirth C, Wenzl T, Zlobinskaya O, Wilkens Jj: Scanning irradiation device for mice in vivo with pulsed and continuous proton beams. Radiat Environ Biophys 2011, 50(3):339-344.

doi:10.1186/1748-717X-6-139

Cite this article as: Auer et al: Survival of tumor cells after proton irradiation with ultra-high dose rates. Radiation Oncology 2011 6:139.

\section{Submit your next manuscript to BioMed Central and take full advantage of:}

- Convenient online submission

- Thorough peer review

- No space constraints or color figure charges

- Immediate publication on acceptance

- Inclusion in PubMed, CAS, Scopus and Google Scholar

- Research which is freely available for redistribution

Submit your manuscript at www.biomedcentral.com/submit
Ciomed Central 